\title{
Impact of Vaccination on Measles Transmission Patterns in Gweru City, Zimbabwe, 1960-89
}

\author{
Tawanda Marufu ${ }^{1,}$, Seter Siziya ${ }^{2}$, Willard Tinago ${ }^{1}$ \\ ${ }^{1}$ Department of Community Medicine, University of Zimbabwe College of Health Sciences, Harare, Zimbabwe \\ ${ }^{2}$ Department of Clinical Sciences, Copperbelt University School of Medicine, Ndola, Zambia \\ Email addresses: \\ marufut@yahoo.com (T. Marufu), ssiziya@gmail.com (S. Siziya),wtinago@gmail.com (W. Tinago) \\ ${ }^{*}$ Corresponding author
}

\section{To cite this article:}

Tawanda Marufu, Seter Siziya, Willard Tinago. Impact of Vaccination on Measles Transmission Patterns in Gweru City, Zimbabwe, 1960-89. European Journal of Preventive Medicine. Vol. 4, No. 3, 2016, pp. 65-72. doi: 10.11648/j.ejpm.20160403.13

Received: March 15, 2016; Accepted: March 25, 2016; Published: April 13, 2016

\begin{abstract}
A study was carried out in Gweru urban district (population-158233) in Zimbabwe to determine the impact of measles vaccine applied at 9 months of age on measles transmission patterns. A retrospective observational study that used data from measles vaccination records and measles disease surveillance was conducted. Linear regression analysis and the chisquared test for linear trend $\left(\chi^{2}\right)$ were used to investigate linear relationships at a $5 \%$ significance level. Vaccine coverage rates were $0 \%$ in pre-vaccination era in $1960-70$ and $2-92 \%$ in $1971-89$ (median $=65, Q_{1}=34, Q_{3}=88$ ) when they significantly linearly increased $(p<0.001)$. In 1960-85 measles incidence rates significantly linearly increased $(p<0.001)$ while in $1986-89$ at vaccine coverage rates of $>90 \%$ incidence rates significantly linearly declined $(\mathrm{p}<0.001)$. Proportion of vaccinated cases among measles notifications significantly linearly increased as vaccine coverage rates increased (Slope: $+1.19,95 \% \mathrm{CI}[0.52,1.86]$ ). At vaccine coverage rates of $>80 \%$ (1984-89), proportion of vaccine failures among cases aged 60-119 months was significantly higher than at vaccine coverage rates of $<80 \%(1971-83)(\mathrm{p}=0.011)$ while in age group 10-59 months proportions of vaccine failures were not different at vaccine coverage rates of $<80 \%$ and $>80 \%$. In age group $60-119$ months incidence rates significantly linearly increased as vaccine coverage rates increased (Slope: $+29.88,95$ CI [13.95, 45.82]). In prevaccination era, and at vaccine coverage rates of $<80 \%$ and $>80 \%$ some $75 \%$ of all reported measles cases occurred by age $36-$ 47 months, 48-59 months and 72-83 months respectively. In conclusion, measles incidence rates declined at vaccine coverage rates of $>90 \%$, while measles vaccine failures significantly increased as vaccine coverage rates increased. Increasing measles vaccination coverage led to shift of age at infection from age group $<59$ months to age group $60-119$ months and decline in rates of measles transmission.
\end{abstract}

Keywords: Measles Vaccination, Impact, Transmission Patterns

\section{Introduction}

In the pre-vaccination era in Africa measles was predominantly a disease of the young and had a devastating impact on unvaccinated populations [1]. Widespread measles vaccination programmes have led to changes in transmission patterns of measles that have included increasing the average age at infection $[1,2]$ which has led to reduction in mortality from measles because mortality is inversely related to age at infection [3]. In the city of Gweru in Zimbabwe it was observed in the late 1980s that vaccination had led to changes in epidemiology of measles. In this city vaccination against measles was commenced in 1971 and accelerated with the advent of the Expanded Programme on Immunization (EPI) in 1982-83. In 1971-89 a single dose of live hyper-attenuated Schwartz strain vaccine $\left(0.5 \mathrm{mls}\right.$ or $\left.1000 \mathrm{TCID}_{50}\right)$ was applied to children at 9 months of age. Gweru is the third largest city in Zimbabwe and has a population of 158233 [4]. Measles vaccine was applied to children at 9 months of age at static health facilities and no vaccination campaigns were carried out outside health facilities. This paper reports on a study that examined the impact of this vaccination regime on measles transmission patterns and explored implications of this impact on measles control. 


\section{Materials and Methods}

\subsection{Study Design}

A retrospective observational study that used data from measles vaccination records and measles disease surveillance data related vaccination rates to dependent variables.

\subsection{Study Area}

The study was conducted in the urban district of Gweru, Zimbabwe.

\subsection{Sources of Data}

\subsubsection{Vaccination Records}

In Gweru, measles vaccinations were applied to children at eight static health facilities since 1971 and vaccination records were available since then. No vaccinations were being applied outside these health facilities. Routine vaccinations were indicated on child health cards and vaccination records/statistics were compiled monthly.

\subsubsection{Measles Disease Surveillance}

The city of Gweru had an active measles surveillance system. On this system, cases were identified on the basis of a standard clinical case definition that was available to all staff at all the city's health centres and infectious disease hospital. There were personnel that were assigned to investigate unreported infectious diseases (including measles cases) within communities (active case search). Measles case surveillance/investigation forms indicated age at infection, vaccination status, sex, presenting features of disease, whether admitted into hospital or not, treatment regime instituted, occurrence of any other cases in relation to an identified case (which would also be investigated), and outcome of illness (alive of dead). Data on vaccination status of cases was only available from 1980 and not before. Complicated cases are managed at the city's single infectious disease hospital. Data on measles cases and deaths were entered on line lists that indicated the same variables as those on case investigation forms. Data from the measles surveillance system were compiled monthly.

\subsubsection{Main Outcome Measures}

The main study outcome measures were; (a) Measles vaccination coverage rates, (b) Measles incidence rates, (c) Changes in age distribution of measles cases, (d) Vaccination status of measles cases, (e) Risk of contracting measles by age: age stratified measles incidence rates, (f) Rate of spread of infection in the population: age stratified cumulative proportions of measles cases.

\subsubsection{Data Analysis}

Medians and interquartile range (IQR) were used to describe continuous non-normally distributed data. Frequencies and percentages were used to describe categorical data. Measles vaccine coverage rates were calculated by dividing the number of vaccine doses administered to those in a specified target age group by the estimated target population. Measles incidence rates were calculated as the number of notified cases per 100000 total population. Denominators used to calculate measles incidence and vaccine coverage rates were obtained from census and inter-census data.

The Kruskal-Wallis (KW) test was used to compare medians of non-normally distributed data. Linear relationship was established using the Chi-squared test for linear trend or simple linear regression analysis, were appropriate All tests were two-sided and the cut off point for statistical significance was 5\%. Data were analyzed using SPSS 20.0 for Windows.

Measles case notifications were pooled by age for the years 1967-70, 1971-83 and 1984-89. These notifications were pooled in line with three levels of measles vaccine coverage i.e. pre-vaccination (1967-70), vaccine coverage $<80 \%$ (1971-83), and vaccine coverage of $>80 \%$ (1984-89). From these pooled case notifications age stratified cumulative proportions of cases were determined. Three cumulative curves or plots were made from the age stratified cumulative proportions of cases. Each of the cumulative curves or plots reflected proportion of population who had experienced infection by each age group and rate of rise of this proportion was a measure of the magnitude of transmission in the population, i.e. the steeper the profile the more rapid the spread of infection in the population. These curves therefore gave an indication of the speed at which infection consumed susceptibles in various age groups

\section{Results}

\subsection{Measles Vaccination Coverage Rates and Measles Incidence Rates}

Vaccine coverage rates were $0 \%$ in pre-vaccination era in 1960-70 and $2-92 \%$ in 1971-89 (Median 65, $Q_{1}=34, Q_{3}=88$ ) when they significantly and linearly increased $\left(\chi^{2}\right.$ for linear trend $=567.1, \mathrm{p}<0.001$ ) figure 1 .

Measles incidence rates in Gweru in 1960-89 were 56.3562.6/100 000 population (median: 215.8, $\mathrm{Q}_{1}=131.8$, $\mathrm{Q}_{3}=304.9$ ). Incidence rates in $1960-85$ were $56.3-562.6 / 100$ 000 population (median: 203.6, $\mathrm{Q}_{1}=128, \mathrm{Q}_{3}=304.9$ ) and these rates significantly linearly increased in this period $\left(\chi^{2}\right.$ for linear trend $=219.75, p<0.001$ ) (figure 1). In 1986-89, measles incidence rates were 141.7-361.1/100 000 population (median: 253.95, $\mathrm{Q}_{1}=197.4, \mathrm{Q}_{3}=309.5$ ) and these rates significantly linearly declined $\left(\chi^{2}\right.$ for linear trend $=85.41$, $\mathrm{p}<0.001$ ). In 1960-89, measles incidence rates did not exhibit a discernable pattern of epidemics and inter-epidemic periods.

\subsection{Changes in Age at Infection}

Data on measles cases that is disaggregated by age was available in Gweru since 1967 and not before. Figure 2 shows distribution of measles cases reported in each age class (for selected years) in the period 1967-89. Measles notifications for the pre-vaccination period, 1967-70, were 
pooled. This figure illustrates detailed changes in the age distribution of measles cases that occurred in the period 1967-89. There was shift of disease from young age groups of $<59$ months towards older age groups of $>60$ months from pre-vaccination era in 1967-70 up till 1989 when vaccination coverage rates were $>90 \%$.

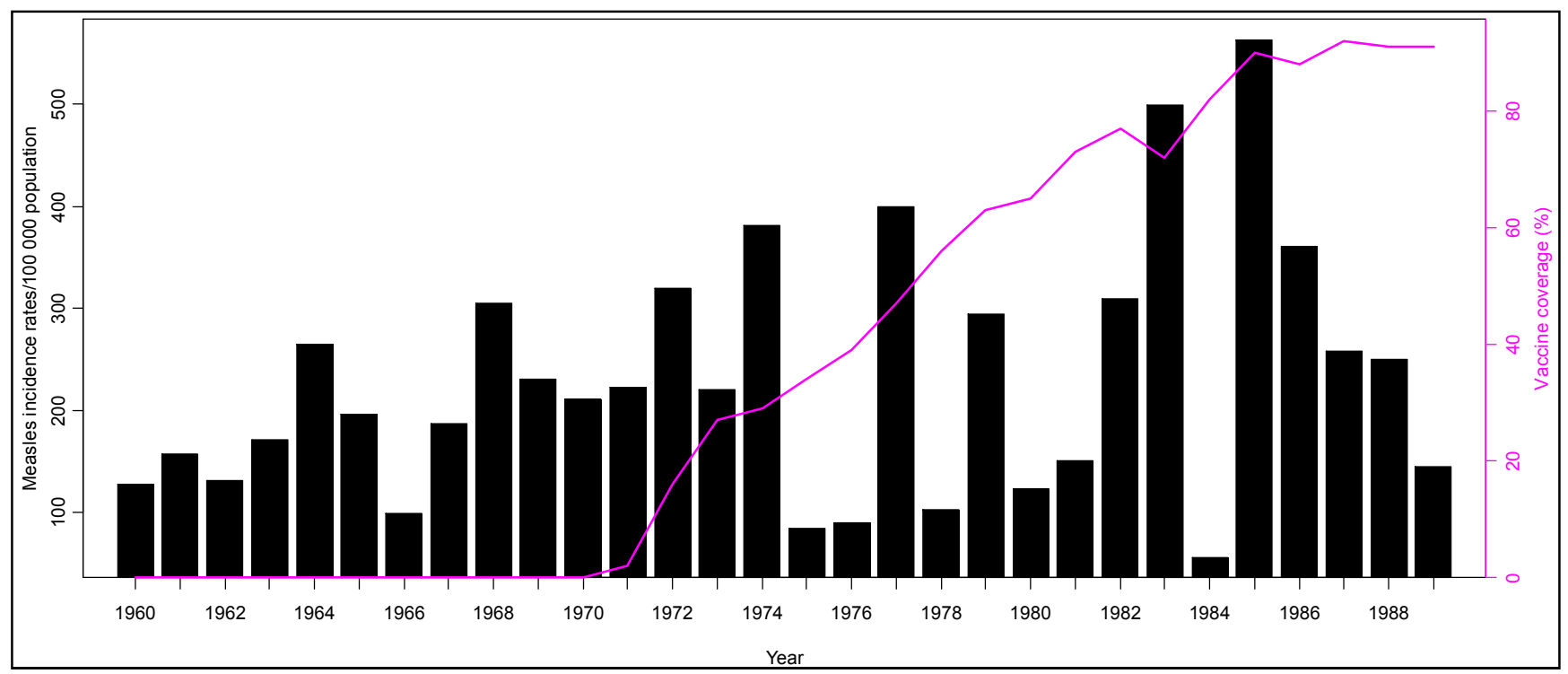

Figure 1. Measles vaccine coverage rates and measles incidence rates in Gweru city 1960-89.

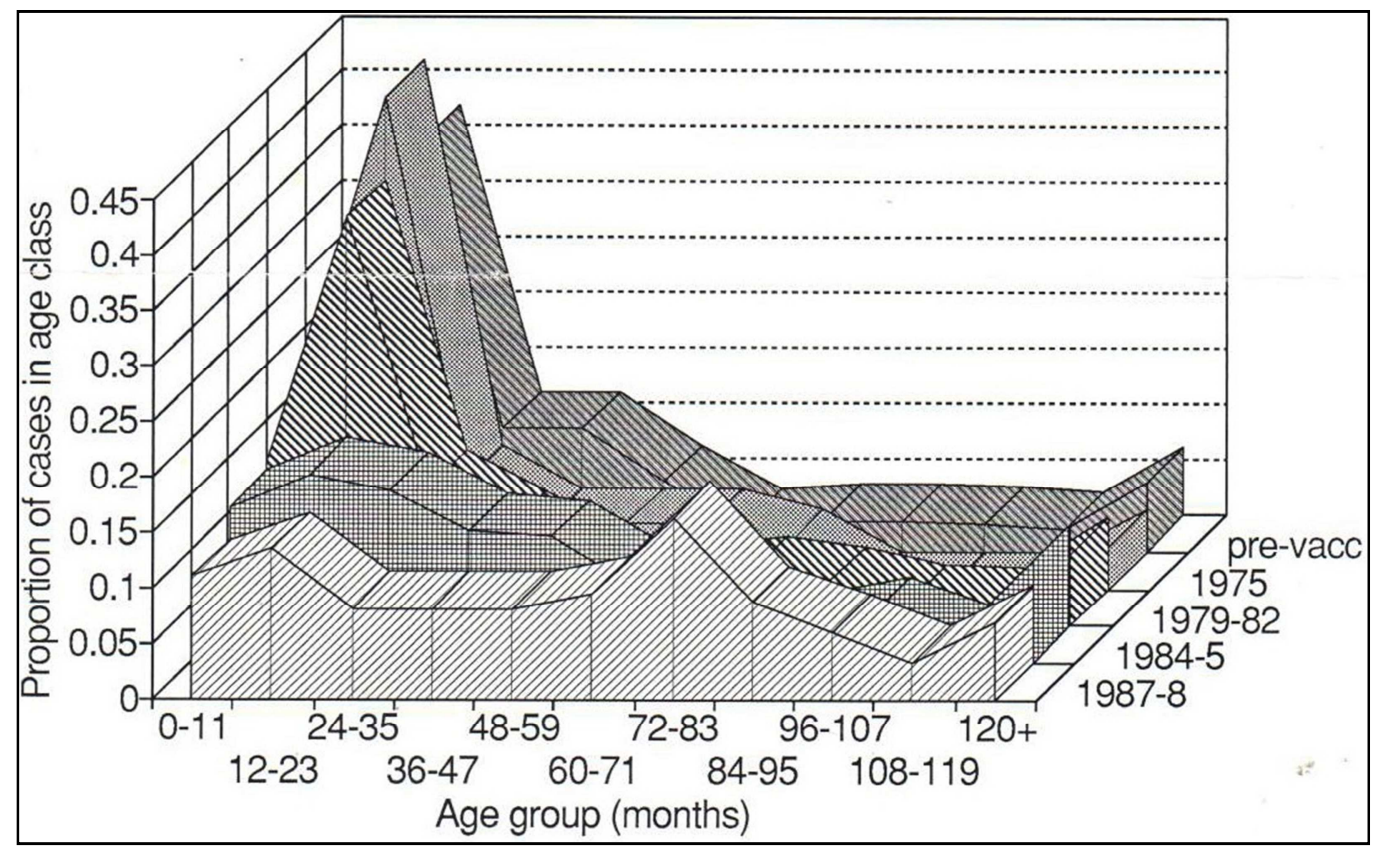

Figure 2. Measles case notifications by age in Gweru city 1967-89.

\subsection{Vaccination Status of Measles Cases}

Data on vaccination status of measles cases was available in Gweru since 1980. In 1980-89 among all reported measles cases 22.2-70.4\% (median: 51.8, $\mathrm{Q}_{1}=42.6, \mathrm{Q}_{3}=58.7$ ) had had measles vaccination (vaccine failures). As vaccination coverage rates increased, the proportion of vaccine failures among all measles case notifications significantly linearly increased (Regression coefficient $=1.19,95 \%$ CI $[0.52$, 1.86], Adjusted $\mathrm{R}^{2}=63.7 \%$ ) - figure 3 .

Proportion of vaccine failures in age group 10-59 months (among all cases reported in this age group) were not significantly different at measles vaccine coverage rates of $<80 \%$ and $>80 \%$ in $1980-89\left(\mathrm{KW} \chi^{2}=6.01, \mathrm{df}=1, \mathrm{p}=0.140\right)$ while in the same period proportion of vaccine failures in age group 60-119 months were significantly higher at vaccine coverage rates of $>80 \%$ than at coverage rates of $<80 \% \quad\left(\mathrm{KW} \chi^{2}=6.55\right.$, df $\left.=1, \mathrm{p}=0.011\right)$. As measles vaccination coverage rates increased, proportion of vaccine failures in age group 60-119 months (among all cases reported in this age group) significantly linearly increased (Regression coefficient $=1.17,95 \%$ CI [0.35, 1.99], Adjusted $\mathrm{R}^{2}=52.1 \%$ ). 


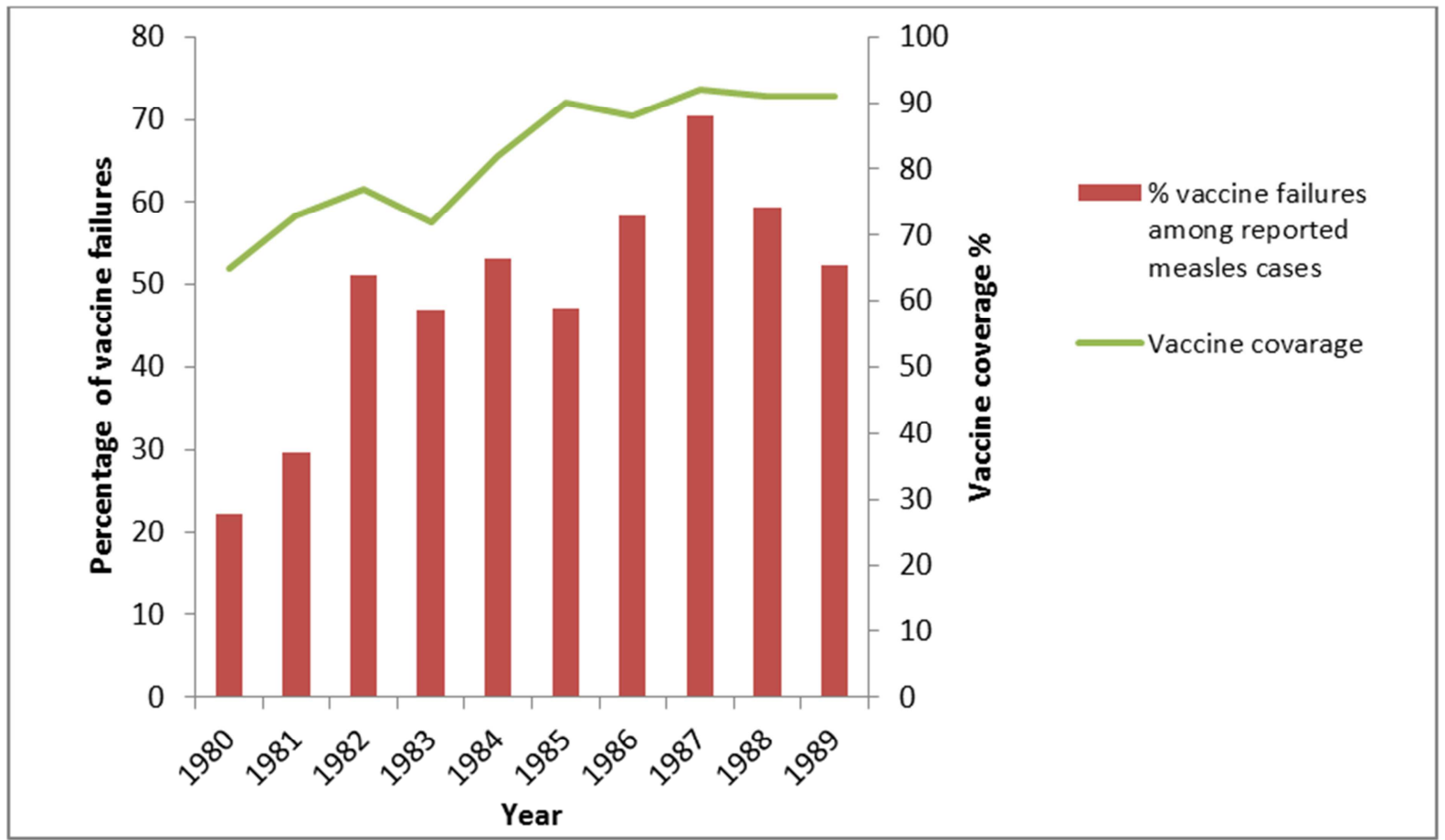

Figure 3. Measles vaccination coverage rates and percentage of vaccine failures (vaccinated cases) among all reported measles cases in Gweru city $1980-89$.

3.4. Risk of Contracting Measles by Age in 1967-89:

Measles Incidence Rates in Age Groups $<=9,10-59$ and 60-119 Months

Measles incidence rates in age groups $<=9,10-59$ and 60 119 months in 1967-89 are indicated in figure 4. In prevaccination era and at vaccine coverage rates of $<80 \%$ and $>80 \%$ measles incidence rates in age group $<=9$ months were not significantly different $\left(\mathrm{KW} \chi^{2}=3.653, \mathrm{df}=2, \mathrm{p}=\right.$ 0.161 ) and so were incidence rates in age group 10-59 months $\left(\mathrm{KW} \chi^{2}=1.63, \mathrm{df}=2, \mathrm{p}=0.443\right)$. Measles incidence rates in age group 60-119 months in pre-vaccination era, and at vaccine coverage rates of $<80$ and $>80 \%$ were significantly different $\left(\mathrm{KW} \chi^{2}=6.11\right.$, df $\left.=2, \mathrm{p}=0.047\right)$. As measles vaccine coverage rates increased measles incidence rates in this age group significantly linearly increased (Regression coefficient $=29.88,95 \%$ CI $[13.95,45.82]$, Adjusted $\mathrm{R}^{2}=$ $39.2 \%)$.

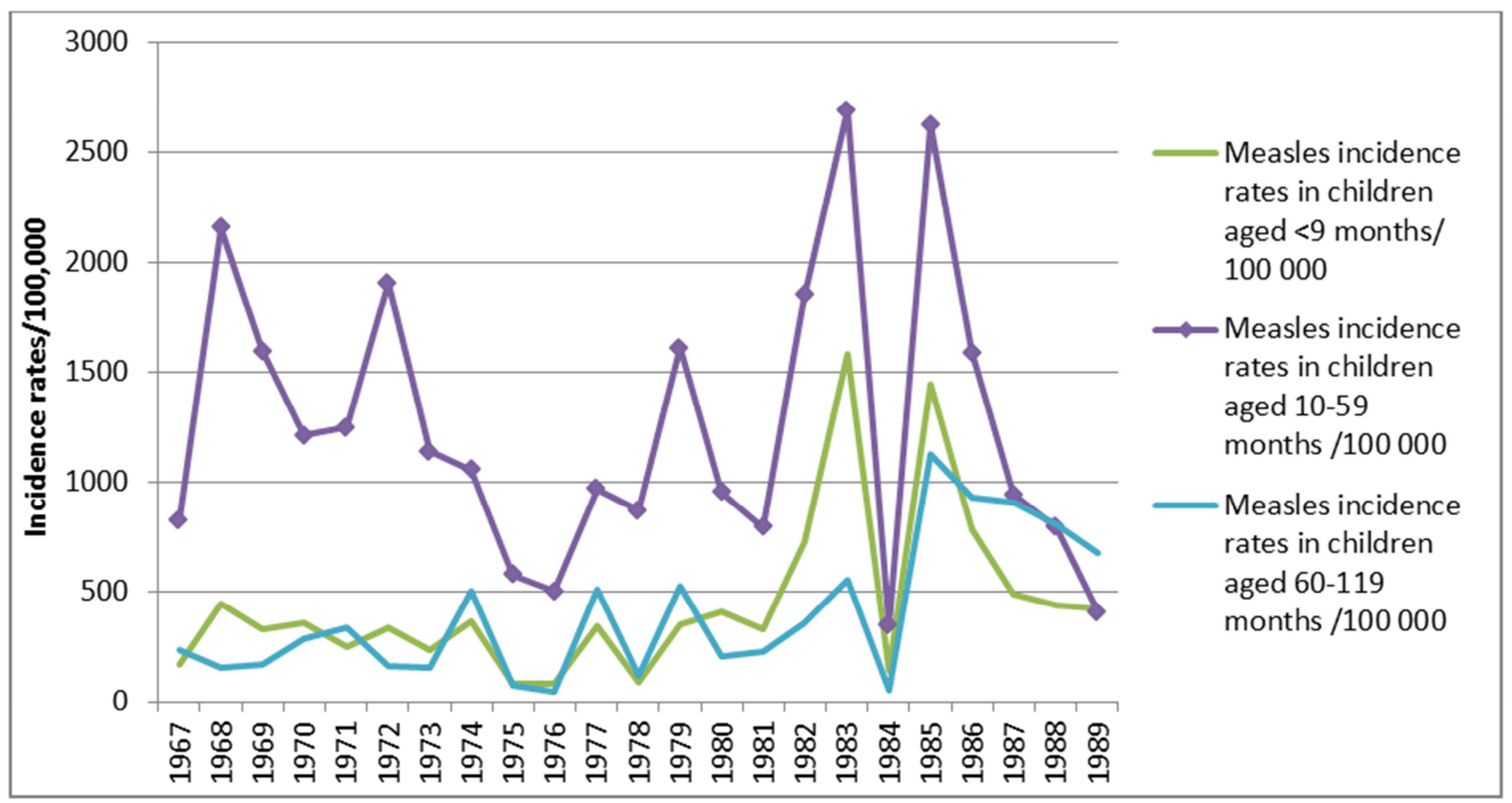

Figure 4. Measles Incidence rates in age groups <=9, 10-59 and 60-119 months in Gweru city 1967-89. 


\subsection{Cumulative Age Distribution of Measles Cases: Rate of Spread of Infection}

Figure 5 shows three curves which are cumulative proportions of measles cases by age for the years 1967-89.

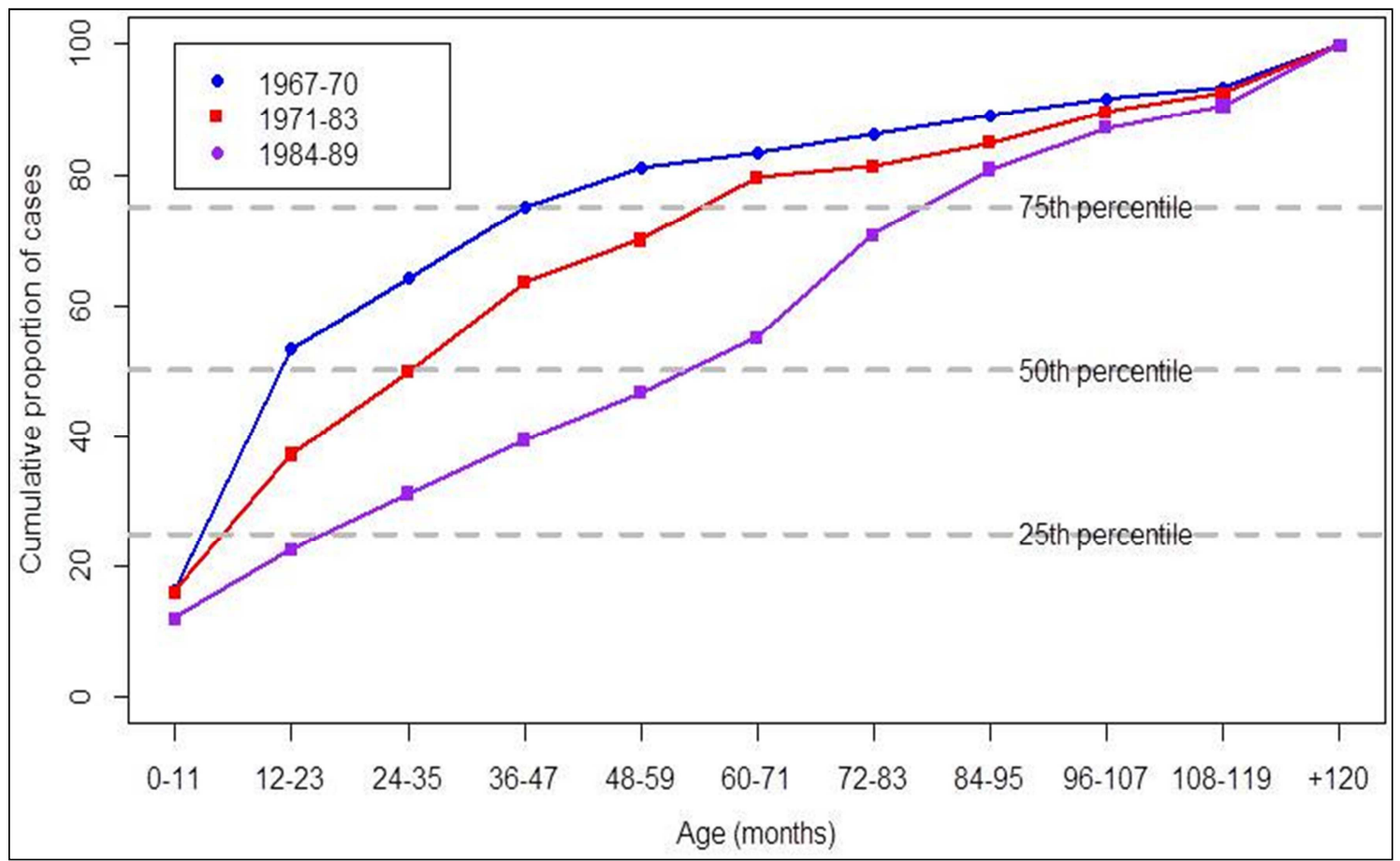

Figure 5. Cumulative proportion plots of reported measles cases for the years 1967-70 (pooled), 1971-83 (pooled) and 1984-89 (pooled) in Gweru city.

In $1967-70,1971-83$ and $1984-89$, some $75 \%$ of all reported measles cases occurred by age group 36-47 months, 48-59 months and 72-83 months respectively and thus measles transmission was most rapid in 1967-70 and least rapid in 1984-89.

\section{Discussion}

\subsection{Measles Incidence Rates}

The current study found that in the pre-vaccination era (1960-70), and at vaccine coverage rates of $<82 \%(1971-85)$ measles incidence rates significantly increased and did not exhibit a discernible pattern of epidemics and inter-epidemic periods. It was also found that at vaccine coverage rates of $>90 \%$ in $1986-89$ measles incidence rates significantly declined.

Several factors could have contributed to the observed significant increase in measles incidence rates in 1960-85. Lack of vaccination in the pre-vaccination era and low measles vaccination coverage rates in 1971-83 may have sustained high measles transmission. High birth rates and population movements from rural to urban areas could have added lots of susceptibles to the urban population thus keeping transmission high [1, 5-9]. Lack of a discernible pattern of epidemics and inter-epidemic periods in 1960-89 may be indicative of an unstable population growth environment where susceptibles were introduced into the urban population in big numbers. While high birth rates and migration could have ensured a continuous supply of susceptibles, densely crowded urban living conditions could have led to rapid transmission of measles $[10,11]$. In this study the role of (a) birth rates, (b) rural to urban population movements and (c) overcrowded living conditions in sustaining high measles transmission in Gweru were not investigated. A possible reason for the observed increase in measles incidence rates in 1960-85 could be improved disease surveillance and reporting of measles cases over the years. There is no doubt that as years progressed surveillance of communicable diseases (including measles) improved.

Measles incidence rates significantly declined in Gweru at measles vaccine coverage rates of $>90 \%$ in $1986-89$. This finding is very much in keeping with experiences elsewhere where sustained high vaccine coverage rates led to decline in measles transmission in communities [12-14].

\subsection{Vaccination Status of Measles Cases}

In this study it was found that as vaccination coverage rates increased, proportion of vaccine failures among reported measles cases significantly increased.

Occurrence of vaccine failures is blamed on a vaccine of less than $100 \%$ efficacy [15-18] or waning immunity [17-19]. With a vaccine of less than $100 \%$ efficacy as vaccine coverage rates increase there would be more vaccine failures among reported cases while at lower vaccine coverage rates fewer vaccine failures are created. Increases of vaccine failures have had important public health implications in relation to measles control. Accumulation of vaccine failures in developing countries with moderate to high measles 
vaccine coverage rates has led to epidemics after a decline in measles transmission [18, 19]. A policy issue of importance that would arise from this is that it would not be possible to either eliminate [20-22] or eradicate [23-25] measles using a strategy that would solely rely on a single application at 9 months of age of a vaccine of less than $100 \%$ efficacy as was the case in Gweru prior to 1989.

\subsection{Changes in Age at Infection: Shift of Disease from Young Age Group of $<59$ Months to Older Age Group 60-119 Months}

The current study found that in pre-vaccination era measles predominantly afflicted the young ( $<59$ months age group) and as vaccine coverage rates increased the disease shifted to older children of 60-119 months of age. It was found that the shift of the disease to these older children was associated with a significant increased susceptibility (increased risk) of contracting measles by this age group compared to younger age group of $<59$ months. Also, it was found that as vaccine coverage rates increased there was a significant increase in occurrence of vaccine failures in this age group.

From the findings of this study, shift of disease to age group 60-119 months is likely to have arisen from increased susceptibility to contracting measles due to accumulation of vaccine failures in this age group. Explanation for accumulation of these vaccine failures among older children (and even adults) has been that for vaccine applied in infancy, vaccination of large proportion of the community reduces chances for susceptibles to be exposed to the infectious agent in infancy such that they are exposed at an older age leading to an increase in average age at infection [18, 26-29]. Shift of measles transmission from younger to older age groups that is associated with accumulation vaccine failures among older age groups has occurred in some developing countries with high vaccine coverage rates of vaccine applied at 9 months of age $[18,19,30]$. Measles epidemics that have occurred in communities and schools in Cape Town in South Africa [19], Swaziland [27], Jordan [30], and Harare, Zimbabwe [31] have mostly involved children who are older than 60 months of age most of whom had had vaccination. Some epidemics that have occurred among older children in schools have been associated with secondary cases in younger siblings in the community [16]. In developing countries high occurrence of measles in children aged $>60$ months in 1989 and before was problematic in that, as a matter of policy, children were routinely only vaccinated at 9 months of age and not at an older age in that period. A public health implication of this would be that to reduce likelihood of epidemics in these susceptible older age groups there would be need to apply vaccination in these groups as a matter of policy.

Shift of disease to older children would have had implications on measles mortality. Studies from Gweru and elsewhere have shown that shift of measles in older children was protective against occurrence of complications and mortality $[1,3]$.

\subsection{Rate of Transmission of Measles in the Population}

This study found that rates of transmission of measles in the population were most rapid in the pre-vaccination era particularly among the young aged $<48$ months with lower transmission occurring among those $>48$ months. The study also found that rates of measles transmission in the population declined as vaccine coverage rates increased with lowest rates of transmission experienced at vaccine coverage rates of $>80 \%$.

Studies from pre-vaccination era have shown that in densely populated communities in developing countries measles transmission was rapid and would consume mostly the underfives such that by the third birthday, three quarters of a birth cohort would have been infected and very few underfives would escape measles in childhood [32].This epidemiological picture is similar to what obtained in Gweru in the pre-vaccination era.

At vaccine coverage rates of $>80 \%$, measles transmission in the Gweru would have been curtailed by herd immunity [33-37] and this could have been particularly so after 1985 (at coverage rates $>90 \%$ ) when the measles vaccine coverage threshold [34, 37-39] had been breached. There are two findings from the current study that would support this observation:

(a) This study found that in the period under review measles was endemic in Gweru and that measles incidence rates significantly increased from pre-vaccination era up till 1985 while at vaccine coverage rates of $>90 \%$ in $1986-89$ there was a significant and sustained decline in measles incidence rates.

(b) At vaccine coverage rates of $>80 \%$, slightly over a third of all measles cases reported in Gweru were of age group 60-119 months. In this age group 63\% of cases were vaccine failures while the remainder had not had vaccination. A likely explanation why both the vaccine failures and the unvaccinated of this age group escaped contracting measles up till this age is that they were protected by herd immunity.

\section{Conclusion}

Impact of measles vaccine applied at 9 months of age on measles transmission patterns was that:

(a) Measles incidence rates declined at vaccine coverage rates of $>90 \%$

(b) Measles vaccine failures significantly increased as vaccine coverage rates increased

(c) Age at infection shifted from age group $<59$ months to age group 60-119 months (as vaccine coverage rates increased) likely due to increased susceptibility of the latter age group arising from accumulation of vaccine failures in this group.

(d) Rates of transmission of measles in the population declined (as vaccine coverage rates increased) likely due the fact that herd immunity retarded transmission.

Implications of this impact were that:

(a) Shift of disease from the younger to older age groups 
meant there would be less mortality among the young.

(b) Shift of disease to older children (most whom were vaccine failures) meant that there would be need to apply vaccination to this group to reduce likelihood of occurrence of epidemics in the future.

\section{Acknowledgements}

We would especially like to thank city of Gweru Public Health Department staff who helped out with extraction of data from the surveillance records and carried out data entry.

\section{References}

[1] Goodson JL, Masresha BG, Wannemuehler K, Uzicanin A, Cochi S. Changing epidemiology of measles in Africa. J Infect Dis 2011; 204 Suppl 1: S205-14.

[2] Moss WJ. Measles still has a devastating impact in unvaccinated populations. PLoS Med 2007; 4(1): e24.

[3] Marufu T, Siziya S, Tshimanga M, Murugasampillay S, Mason E, Manyame B. Factors associated with measles complications in Gweru, Zimbabwe. East Afr Med J 2001; 78(3): 135-8.

[4] ZimStat. Census 2012. Preliminary report. Zimbabwe National Statistics Agency, Harare, Zimbabwe, 2010. http://unstats.un.org/unsd/demographic/sources/census/2010_p hc/Zimbabwe/ZWE_CensusPreliminary2012.pdf. Accessed 23 March 2016.

[5] Conlan AJ, Grenfell BT. Seasonality and the persistence and invasion of measles. Proc Biol Sci 2007; 274(1614): 1133-41.

[6] Ferrari MJ, Grenfell BT, Strebel PM. Think globally, act locally: the role of local demographics and vaccination coverage in the dynamic response of measles infection to control. Philos Trans R Soc Lond B Biol Sci 2013; 368(1623): 20120141.

[7] Earn DJ, Rohani P, Bolker BM, Grenfell BT. A simple model for complex dynamical transitions in epidemics. Science 2000; 287(5453): 667-70.

[8] May RM, Anderson RM. Spatial heterogeneity and the design of immunization programs. Mathematical Biosciences 1984; 72(1): 83-111.

[9] Anderson RM, May RM. Age-related changes in the rate of disease transmission: implications for the design of vaccination programmes. J Hyg (Lond) 1985; 94(3): 365-436.

[10] Foster SO. Measles, the ultimate challenge in urban immunization In: Universal child immunization-Reaching the urban poor, Urban Examples. New York, UNICEF, 1990.

[11] Global Program for Vaccines of World Health Organization. Global measles strategy picks up pace. In: Summary of consultation on strategies to accelerate global measles control held on 27-28 April 1994; PAHO headquarters, Washington DC.

[12] Center for Disease Control and Prevention. Global measles mortality, 2000-2008 MMWR Morb Mortal Wkly Rep 2009; 58(47): $1321-6$
[13] Keeling MJ, Rhani P. Modelling infectious diseases in humans and animals. Princeton: Princeton University Press 2008.

[14] Goldhaber-Fiebert JD, Lipsitch M, Mahal A, Zaslavsky AM, Salomon JA. Quantifying child mortality reductions related to measles vaccination. PLoS One; 2010; 5(11): e13842.

[15] Rosenthal SR, Clements CJ. Two-dose measles vaccination schedules. Bull World Health Organ 1993; 71(3-4): 421-8.

[16] Marufu T, Siziya S, Tshimanga M, Xaba E, Ruwodo C, Silape $Z$, et al. Challenges posed by changes in measles transmission patterns. Cent Afr J Med 1998; 44(1): 5-8.

[17] Marufu T, Siziya S, Manyame B, Xaba E, Silape-Marufu Z, Zimbizi $\mathrm{P}$, et al. Questioning the level of efficacy of the measles vaccine in use in Zimbabwe. Cent Afr J Med 1995; 41(8): 241-5.

[18] Global Programme for Vaccines and Immunization. Immunization Policy. Expanded Programme on Immunization, WHO/EPI/GEN/92.3. WHO. Geneva: WHO; 1995.

[19] Coetzee N, Hussey GD, Visser G, Barron P, Keen A. The 1992 measles epidemic in Cape Town- a changing epidemiological pattern S Afr Med J 1994; 84(3): 145-9.

[20] De Quadros CA, Olive JM, Hersh BS, Strassburg MA, Henderson DA, Brandling-Bennett D, et al. Measles elimination in the Americas- Evolving strategies. JAMA 1996; 275 (3): 224-9.

[21] Cutts FT, Lessler J, Metcalf CJ. Measles elimination: progress, challenges and implications for rubella control. Expert Rev Vaccines 2013; 12(8): 917-32.

[22] World Health Organization. Meeting of the Strategic Advisory Group of Experts on Immunization, November 2012 conclusions and recommendations. Wkly Epidemiol Rec; 88(1): $1-16$

[23] Moss WJ, Strebel P. Biological feasibility of measles eradication. J Infect Dis 2011; 204 Suppl 1: S47-53.

[24] De Quadros CA, Andrus JK, Danovaro-Holliday MC, Castillo-Solorzano C. Feasibility of global measles eradication after interruption of transmission in the Americas. Expert Rev Vaccines 2008; 7(3): 355-62.

[25] Andrus JK, de Quadros CA, Solorzano CC, Periago MR, Henderson DA. Measles and rubella eradication in the Americas Vaccine 2011; 29 Suppl 4: D91-6.

[26] Expanded Programme on Immunization. Measles control in the 1990s: Plan of action for global measles control 1992; WHO/EPI/GEN/92.3.

[27] Cutts F. Expanded Programme on Immunization-Measles control in the 1990s: Principles for the next decade, 1990; WHO/EPI/GEN/90.2.

[28] Marufu T, Siziya S. Impact of multiple dose measles vaccination on measles transmission patterns in Gweru, Zimbabwe. J Trop Pediatr 2001; 47(6): 335-8.

[29] Marufu T, Siziya S, Tinago W. Comparison of single dose and multiple dose measles vaccination strategies on measles transmission patterns. European Journal of Preventive $\begin{array}{llll}\text { Medicine } & 2015 ; & 3(3): & 80-84\end{array}$ 10.116488/j.ejpm.20150303.18.

[30] Khuri-Bulos NA. Measles in Jordan: a prototype of the problems with measles in developing countries. Pediatr Infect Dis J 1995; 14(1): 22-6. 
[31] Kambarami RA, Nathoo KJ, Nkrumah FK, Pirie DJ. Measles epidemic in Harare, Zimbabwe, despite high measles immunization coverage rates. Bull World Health Organ 1991; 69 (2): 213-9.

[32] Morley D. Severe Measles. In: Paediatric Priorities in the Developing World, Butterworts 1979: 207-30.

[33] Garnett GP. Role of herd immunity in determining the effect of vaccines against sexually transmitted disease. J Infect Dis 2005; 191 Suppl 1: S97-106.

[34] Willingham E, Helf L. What is Herd Immunity? Available on www.pbs.org/wgbh/nova/body/herd-immunity.html [Accessed 06 December 2015].
[35] John TJ, Samuel R. Herd immunity and herd effect: new insights and definitions. Euro J Epidemiol 2000; 16 (7): 601-6.

[36] Anderson RM, May RM. Vaccination and herd immunity to infectious diseases. Nature 1985; 318(6044): 323-9.

[37] Fine P, Eames K, Heymann DL. "Herd immunity": a rough guide. Clin Infect Dis 2011; 52(7): 911-6.

[38] Fine PE. Herd immunity: history, theory, practice. Epidemiol Rev 1993; 15(2): 265-302.

[39] Nokes DJ, Anderson RM. Measles, mumps, and rubella vaccine: what coverage to block transmission? Lancet 1988; 2(8624): 1374. 